\title{
Analisa Pola Sistem Penjualan Makanan Ringan dengan Menggunakan Algoritma Apriori
}

\author{
Zulham $^{1}$, Ibnu Rusydi ${ }^{2}$, M Arif Rahman ${ }^{3}$ \\ ${ }^{1,2,3}$ Rekayasa Perangkat Lunak, Universitas Dharmawangsa
}

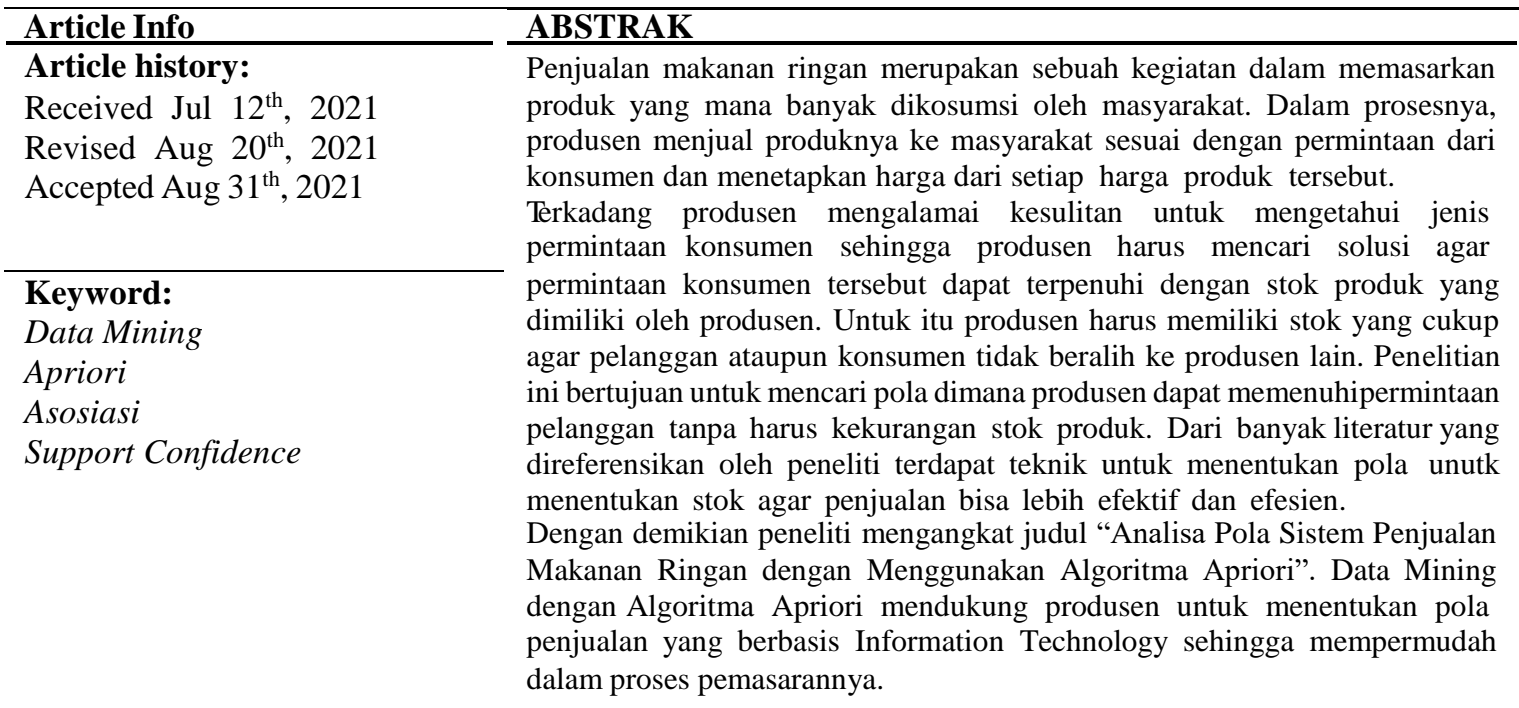

Copyright $@ 2021$ STMIK Triguna Dharma. All rights reserved.

\author{
Corresponding Author: \\ *ZulhamNama : Zulham \\ Program Studi : RPL \\ Afiliasi : UniversitasDharmawangsa \\ Email:zulham@dharmawangsa.ac.id
}

\section{PENDAHULUAN}

Penjualan makanan ringan merupakan sebuah kegiatan dalam memasarkan produk yang mana banyak dikosumsi oleh masyarakat. Dalam prosesnya, produsen menjual produknya ke masyarakat sesuai dengan permintaan dari konsumen dan menetapkan harga dari setiap harga produk tersebut. Terkadang produsen mengalamai kesulitan untuk mengetahui jenis permintaan konsumen sehingga produsen harus mencari solusi agar permintaan konsumen tersebut dapat terpenuhi dengan stok produk yang dimiliki oleh produsen. Untuk itu produsen harus memiliki stok yang cukup agar pelanggan ataupun konsumen tidak beralih ke produsen lain. Penelitian ini bertujuan untuk mencari pola dimana produsen dapat memenuhi permintaan pelanggan tanpa harus kekurangan stok produk. Dari banyak literatur yang direferensikan oleh peneliti terdapat teknik untuk menentukan pola unutk menentukan stok agar penjualan bisa lebih efektif dan efesien. Dengan demikian peneliti mengangkat judul "Analisa Pola Sistem Penjualan Makanan Ringan dengan Menggunakan Algoritma Apriori”. Algoritma Apriori mendukung produsen untuk bisa menentukan pola penjualan yang berbasis Information Technology sehingga mempermudah dalam proses pemasarannya.

Data Mining merupakan suatu cabang keilmuan yang mana memiliki beberapa jenis metode untuk memanfatannya diantaranya : asosiasi, prediksi, klasifikasi, klastering dan estimasi. Data Mining dipakai untuk mencari suatu pola kebiasaan berdasarkan data yang ada sebelumnya sehingga informasi yang tersembunyi 
bisa didapatkan untuk menyelesaikan masalah. Adapun algoritma yang dipakai dalam penelitian ini adalah algoritma apriori yang diterapkan[1].

Algoritma Apriori adalah algoritma yang digunakan untuk menentukan frequent itemset pada association rule. Algoritma ini mempunyai tahap-tahap mulai dari pembentukan kandidat itemset, kemudian menghitung nilai sampai mendapatkan pola frekuensi tinggi[2][3].

\section{METODE PENELITIAN}

\subsection{Data Mining}

Data Mining merupakan rangkaian proses untuk menggali suatu data dalam jumlah yang sangat besar sehingga mendapatkan informasi dari kumpulan data tersebut. Informasi yang dihasilkan dengan mengestrak dan mencari pola yang sangat penting dari kumpulan data atau basisdata. Data Mining dipergunakan untuk mencari informasi yang ada di dalam suatu database dalam jumlah yang sangat besar sehingga disebut juga Knowledge Discovery Databases (KDD)[4][5].

Dengan banyaknya database yang ada maka informasi yang dihasilkan untuk dikembangkan akan semakin kuat sehingga jauh dari kesalahan. Untuk itu data yang digali juga harus valid dan besar agar hasil dari analisa data tersebut bisa menjadi rujukan dalam proses pengambilan keputusan. Data mining adalah salah satu kedisiplinan cabang ilmu komputer sebagai proses komputasi penjelajahan pola dalam kumpulan data dengan menyertakan metode kecerdasan buatan, meachine learning, statistik dan sistem database, dengan tujuan keseluruhan prosesnya adalah untuk mengekstrak informasi dari kumpulan data dan mengubahnya menjadi sekumpulan struktur data yang dapat dimengerti dan digunakan.

\subsection{Apriori}

Menurut Bhandari (2015) Algoritma Apriori merupakan algoritma yang sangat terkenal dalam keilmuan data mining guna mengetahui konsep aturan asosiasi untuk digunakan oleh banyak orang pada transaksi dan aplikasi yang real time yang dikumpulkan dari banyaknya transaksi agar dapat menghasilkan frekuensi itemset yang berhubungan[6]. Pada khususnya dari salah satu tahap analisa banyak membuat menarik perhatian peneliti guna menghasilkan algoritma yang efesien. Adapun algoritma tersebut menghasilkan analisa pola frequent pattern mining. Metodologi dasar analisis asosiasi terbagi menjadi dua yaitu :

\subsubsection{Analisis Pola Frekuensi Tinggi}

Pada langkah ini untuk mencari nilai support dalam database. Nilai support sebuah item dapat dihasilkan dengan menggunakan rumus sebagai berikut :

$$
\text { Support } A=\frac{\text { Jumlah Transaksi }}{\text { Transaksi }}(A) \times 100 \%
$$

Sedangkan nilai support dari dua item diperoleh dari rumus berikut:

$$
\text { Support }(A, B)=P(A \rightarrow B)=\frac{\text { Jumlah Transaksi }(A \rightarrow B)}{\text { Transaksi }} \times 100 \% \ldots[8]
$$

\subsubsection{Pembentukan Aturan Asosiasi}

Ketika seluruh pola frekuensi tinggi berhasil didapatkan, kemudian kita cari aturan asosiasi yang memiliki syarat minimum untuk confidence dengan melakukan perhitungan nilai confidence berdasarkan aturan asosiasi $\mathrm{A} \rightarrow \mathrm{B}$.

Nilai confidence dari aturan $\mathrm{A} \rightarrow \mathrm{B}$ diperoleh dari rumus berikut :

confidence aturan asosiatif $\mathrm{A} \rightarrow \mathrm{B}$. Nilai aturan $\mathrm{A} \rightarrow \mathrm{B}$ diperoleh

rumus :

$$
\text { Confidence }(A, B)=P(A \rightarrow B)=\frac{\text { Jumlah Transaksi }(A \rightarrow B)}{\text { Transaksi } A} \times 100 \% \cdot[9][10]
$$

Analisa Asosiasi adalah merupakan teknik data mining yang bisa digunakan sebagai dasar untuk teknik data mining lain. Analisa asosiasi dapat diartikan proses untuk mencari aturan assosiasi dalam memenuhi syarat minimum support dan minimum confidence. Aturan asosiasi mempunyai peran penting karena dapat

Jurnal SAINTIKOM Vol. 20, No. 2, Agustus 2021 : $52-63$ 
mengetahui pola aturan asosiasi dari 2 parameter yaitu support dan confidence. Dimana support (nilai penunjang) dan confidence (nilai kepastian) dengan persentase kombinasi itemnya memiliki hubungan kuat antara item dalam aturan asosiasi.

\section{ANALISA DAN HASIL}

Analisa dari penelitian ini adalah dengan melakukan survey terhadap sistem yang sudah ada sehingga didapatkan titik terang permasalahan yang sesungguhnya. Dengan begitu hasil dari penelitian ini bisa sesuai dengan kebutuhan penggunanya. Untuk kedepannya perlu dilakukan pengembangan dalam sistem secara berkala untuk bisa menyesuaikan dengan kondisi zaman sehingga tetap relevan di masa-masa yang akan datang.

Pada akhirnya peneliti diharapkan bisa memecahkan permasalahan yang saat ini dihadapi produsen makanan ringan tersebut. Analisa penelitian ini mencakup atas penemuan hubungan produk berdasarkan nilai support dan confidence dari data transaksi[11].

\subsection{Algoritma Sistem}

Algoritma sistem adalah proses sistematik dari pengembangan kebutuhan. Pada proses sistemnya dengan konsep asosiasi, dipakai beberapa data dan informasi mengenai transaksi penjualan terhadap makanan ringat tersebut. Berikut ini adalah tahapan yang dilakukan dalam menyelesaikan algoritma Apriori[12][13].

1. Identifikasi Data Transaksi.

2. Pembentukan Pola Kombinasi Dua Itemset

3. Pembentukan Aturan Asosiasi (Association Rule)

Setelah pendataan selesai, lakukan identifikasi data sesuai kebutuhan sistem. Oleh karena itu, untuk menarik suatu kesimpulan berdasarkan kaidah-kaidah dalam analisis data, diperlukan adanya data transaksi yang telah dilakukan. Analisis data didasarkan pada teknologi aturan asosiasi, dengan menggunakan algoritma apriori dengan beberapa langkah dan iterasi tertentu. Data yang diambil merupakan data penjualan pada bulan Januari 2021 sampai dengan Februari 2021. Data tersebut adalah sampel data dari data penjualan dan dapat dilihat pada tabel 1 Data Transaksi Penjualan Makanan Ringan.

Tabel 1. Data Transaksi Penjualan Makanan Ringan

\begin{tabular}{|c|c|c|}
\hline Tanggal & Produk & Jumlah \\
\hline \multirow{10}{*}{$1 / 01 / 2021$} & Brownies Kukus & 1 \\
\hline & Caramel Pisang & 1 \\
\hline & Red Valvet Mini & 1 \\
\hline & Donat Aneka Rasa & 1 \\
\hline & Donat Abon Keju & 1 \\
\hline & Roti Aneka Rasa & 2 \\
\hline & Tawar Moca Ceres & 1 \\
\hline & Donat Goreng Salju & 2 \\
\hline & Bika Ambon & 2 \\
\hline & Serba-serbi & 6 \\
\hline & Roti Manis Coklat 2 Rasa & 2 \\
\hline & Roti Manis Susu & 1 \\
\hline
\end{tabular}




\begin{tabular}{|c|c|c|}
\hline \multirow{8}{*}{$2 / 01 / 2021$} & Aqua & 3 \\
\hline & Bolu Gulung Aneka Rasa & 1 \\
\hline & Cake Jagung Panjang & 1 \\
\hline & Bika Caramel & 1 \\
\hline & Es Ganepo & 4 \\
\hline & Selaikaya Besar & 1 \\
\hline & Tawar Pandan & 1 \\
\hline & Cake Coklat Blue/Star & 1 \\
\hline \multirow{10}{*}{$3 / 01 / 2021$} & Tawar Kismis & 1 \\
\hline & Brownies Ceres & 1 \\
\hline & Cake Labu & 1 \\
\hline & Pisang Vanila/Blue & 1 \\
\hline & Beownies Panggang SP & 1 \\
\hline & Roti Raisin/Fruit CA & 1 \\
\hline & Pan Cake Durian & 2 \\
\hline & Kubas & 3 \\
\hline & Roti Aneka Rasa & 3 \\
\hline & Donat Aneka Rasa & 5 \\
\hline \multirow{7}{*}{$4 / 01 / 2021$} & Mini Cake & 3 \\
\hline & Selaikaya Besar & 1 \\
\hline & Dodol Susu & 1 \\
\hline & Muffin cok/Vla & 3 \\
\hline & Double coklat/pandan & 1 \\
\hline & Lapis legit Durian & 1 \\
\hline & Tako Coklat mini & 1 \\
\hline \multirow{10}{*}{$5 / 01 / 2021$} & Serba-serbi & 2 \\
\hline & Es Ganepo & 2 \\
\hline & Tawar Petak Originl & 1 \\
\hline & Bolu Gulung Aneka Rasa & 2 \\
\hline & Selai srikaya Besar & 1 \\
\hline & Tawar petak Special & 1 \\
\hline & Roti Isi 6 & 1 \\
\hline & Roma Sari Gandum FAM & 1 \\
\hline & Caramel Pisang & 1 \\
\hline & Bika Ambon & 2 \\
\hline
\end{tabular}




\begin{tabular}{|c|c|c|}
\hline & Brownies Kukus & 1 \\
\hline & Black Forest & 1 \\
\hline & Maccaroonn & 1 \\
\hline \multirow{10}{*}{$6 / 01 / 2021$} & Roti Aneka Rasa & 2 \\
\hline & Bolu Gulung Ceres/Keju & 1 \\
\hline & Ice Cream & 1 \\
\hline & Brownies Kukus & 1 \\
\hline & Aqua & 5 \\
\hline & Kubas & 5 \\
\hline & Roti & 10 \\
\hline & Donat Aneka Rasa & 3 \\
\hline & Roll Cake Noir & 1 \\
\hline & Nastar Aneka Rasa & 2 \\
\hline \multirow{10}{*}{$7 / 01 / 2021$} & Tawar Moca Ceres & 1 \\
\hline & Roti Aneka Rasa & 1 \\
\hline & Roti Manis Susu & 1 \\
\hline & Mini Cake & 1 \\
\hline & Donat Abon/Keju/Kcg & 2 \\
\hline & Pan Cake Durian & 1 \\
\hline & Serba-serbi & 2 \\
\hline & Roti Bungkus & 1 \\
\hline & Roll Cake Noir & 1 \\
\hline & Roti Isi 6 & 1 \\
\hline \multirow{10}{*}{$8 / 01 / 2021$} & Caramel Pisang & 1 \\
\hline & Roti Manis Susu & 1 \\
\hline & Bika Caramel & 1 \\
\hline & Roti Manis Coklat 2 Rasa & 1 \\
\hline & Brownies Kukus & 1 \\
\hline & Sponge Cake Pandan & 2 \\
\hline & Donat Goreng Salju & 2 \\
\hline & Donat Aneka Rasa & 1 \\
\hline & Roti Aneka Rasa & 3 \\
\hline & Brownies Ceres & 1 \\
\hline \multirow{2}{*}{$9 / 01 / 2021$} & Nastar Aneka Rasa & 1 \\
\hline & Kubas & 1 \\
\hline
\end{tabular}




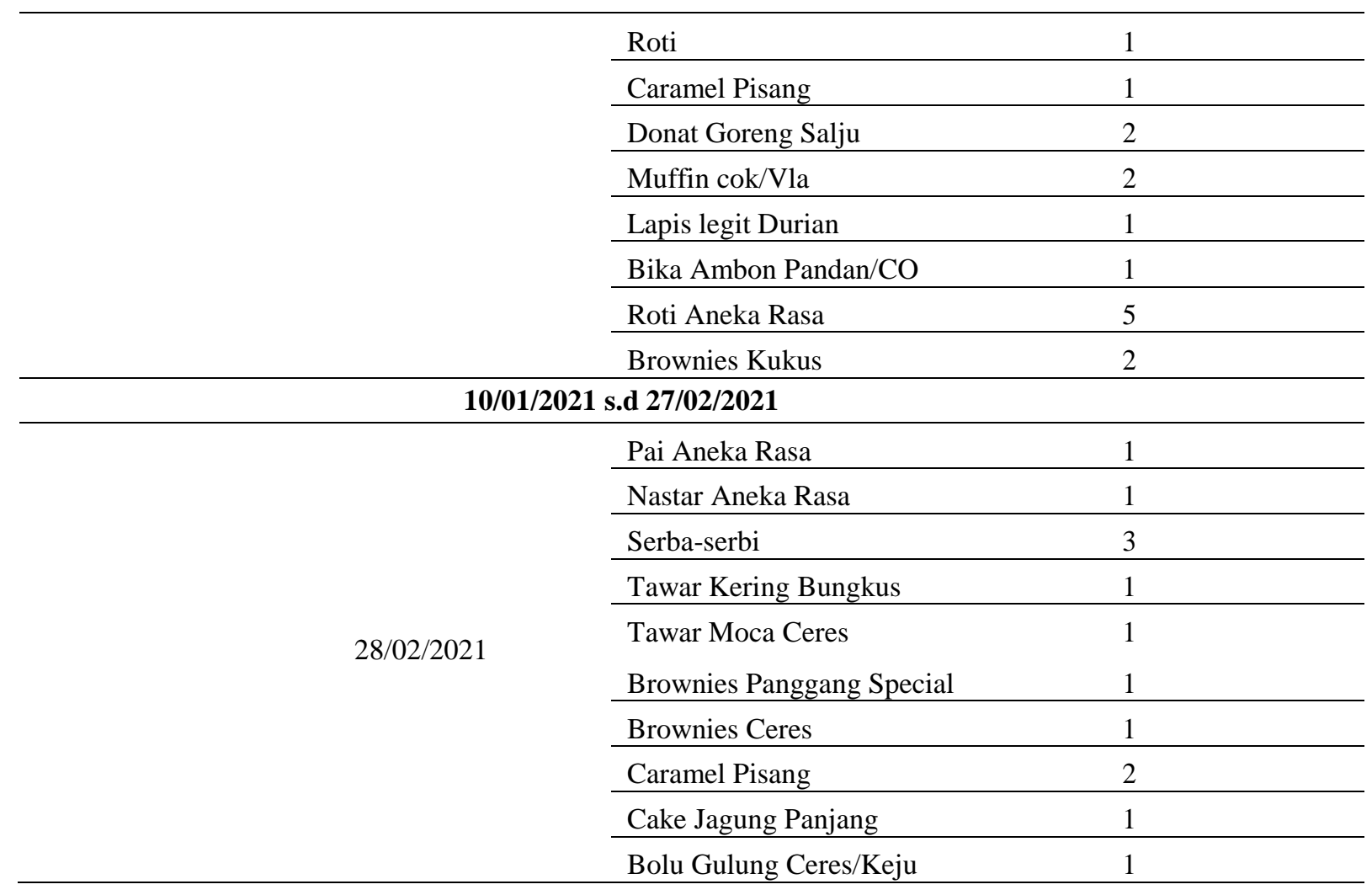

\subsection{Pencarian Pola Frekuensi Tinggi}

Dari tabel 1 dihitung nilai frekuensi berdasarkan 29 data transaksi penjualan tersebut dan kemudiandilakukan pencarian nilai support dengan rumus [14]:

Tabel 2. Data Transaksi dengan nilai support

\begin{tabular}{clcr}
\hline No & \multicolumn{1}{c}{ Nama Produk } & Frekuensi & \multicolumn{1}{c}{ Support } \\
\hline 1 & Aqua & 6 & $20.69 \%$ \\
\hline 2 & Banana Cake & 4 & $13.79 \%$ \\
\hline 3 & Brownies Panggang SP & 0 & $0.00 \%$ \\
\hline 4 & Bika Ambon & 17 & $58.62 \%$ \\
\hline 5 & Bika Ambon Pandan/CO & 3 & $10.34 \%$ \\
\hline 6 & Bika Caramel & 3 & $10.34 \%$ \\
\hline 7 & Black Forest & 5 & $17.24 \%$ \\
\hline 8 & Bolu GLG Ceres/Keju/Chip & 1 & $3.45 \%$ \\
\hline 9 & Bolu Glg Ppineapple & 1 & $3.45 \%$ \\
\hline 10 & Bolu Gulung Aneka Rasa & 5 & $17.24 \%$ \\
\hline 11 & Bolu Gulung Ceres/Keju & 4 & $13.79 \%$ \\
\hline
\end{tabular}

Jurnal SAINTIKOM Vol. 20, No. 2, Agustus 2021: $52-63$ 


\begin{tabular}{rlrr}
\hline 12 & Bolu Gulung Mocca & 2 & $6.90 \%$ \\
\hline 13 & Brownies Ceres & 3 & $10.34 \%$ \\
\hline 14 & Brownies Kukus & 7 & $24.14 \%$ \\
\hline 15 & Brownies Kukus N/Blue & 2 & $6.90 \%$ \\
\hline 16 & Brownies Panggang Special & 4 & $13.79 \%$ \\
\hline 17 & Cake Caramel & 1 & $3.45 \%$ \\
\hline 18 & Cake Coklat Blue/Star & 2 & $6.90 \%$ \\
\hline 19 & Cake Coklat Caramel & 1 & $3.45 \%$ \\
\hline 20 & Cake Jagung Panjang & 6 & $20.69 \%$ \\
\hline 21 & Cake Labu & 1 & $3.45 \%$ \\
\hline 22 & Caramel & 1 & $3.45 \%$ \\
\hline 23 & Caramel Pisang & 13 & $44.83 \%$
\end{tabular}

\begin{tabular}{|c|c|c|c|}
\hline 24 & Caramel Pisang Panjang & 2 & $6.90 \%$ \\
\hline 25 & Carmel & 1 & $3.45 \%$ \\
\hline 26 & Cokelat & 1 & $3.45 \%$ \\
\hline 27 & Dodol Susu & 1 & $3.45 \%$ \\
\hline 28 & Donat Abon Keju & 1 & $3.45 \%$ \\
\hline 29 & Donat Abon Keju/KCG & 2 & $6.90 \%$ \\
\hline 30 & Donat Aneka Rasa & 14 & $48.28 \%$ \\
\hline 31 & Donat Ayam Goreng & 1 & $3.45 \%$ \\
\hline 32 & Donat Cokelat Tela & 1 & $3.45 \%$ \\
\hline 33 & Donat Goreng Salju & 5 & $17.24 \%$ \\
\hline 34 & Donat Paha Ayam & 3 & $10.34 \%$ \\
\hline 35 & Doryaki & 1 & $3.45 \%$ \\
\hline 36 & Double coklat/pandan & 2 & $6.90 \%$ \\
\hline 37 & Es Ganepo & 4 & $13.79 \%$ \\
\hline 38 & Ice Cream & 2 & $6.90 \%$ \\
\hline 39 & Kubas & 12 & $41.38 \%$ \\
\hline 40 & Lapis legit Durian & 5 & $17.24 \%$ \\
\hline 41 & lapis Surabaya & 1 & $3.45 \%$ \\
\hline 42 & Maccaroonn & 1 & $3.45 \%$ \\
\hline 43 & Mini Cake & 7 & $24.14 \%$ \\
\hline 44 & Muffin cok/Vla & 5 & $17.24 \%$ \\
\hline 45 & Nastar Aneka Rasa & 3 & $10.34 \%$ \\
\hline 46 & Paha Ayam & 9 & $31.03 \%$ \\
\hline 47 & Pai Aneka Rasa & 2 & $6.90 \%$ \\
\hline 48 & Pai Durian & 1 & $3.45 \%$ \\
\hline 49 & Pan Cake Durian & 6 & $20.69 \%$ \\
\hline 50 & Pisang Vanila/Blue & 2 & $6.90 \%$ \\
\hline 51 & Red Valvet Mini & 1 & $3.45 \%$ \\
\hline & Roll Cake Noir & 4 & $13.79 \%$ \\
\hline
\end{tabular}




\begin{tabular}{rlcr}
\hline 53 & Roma Sari Gandum FAM & 1 & $3.45 \%$ \\
\hline 54 & Roti & 7 & $24.14 \%$ \\
\hline 55 & Roti Aneka Rasa & 20 & $68.97 \%$ \\
\hline 56 & Roti Bungkus & 6 & $20.69 \%$ \\
\hline 57 & Roti Isi 6 & 2 & $20.69 \%$ \\
\hline 58 & Roti Manis Coklat 2 Rasa & 5 & $6.90 \%$ \\
\hline 59 & Roti Manis Susu & 2 & $17.24 \%$ \\
\hline 60 & Roti Raisin/Fruit CA & 5 & $6.90 \%$ \\
\hline 61 & Selai srikaya Besar & 10 & $17.24 \%$ \\
\hline 62 & Serba-serbi & 3 & $34.48 \%$ \\
\hline 63 & Sponge Cake Pandan & 3 & $10.34 \%$ \\
\hline 64 & Sponge Caramel & 1 & $10.34 \%$ \\
\hline 65 & Sponge Marmer Pandan & 1 & $3.45 \%$ \\
\hline 66 & Sponge Marmer Pandan/COK & 1 & $3.45 \%$ \\
\hline 67 & Tako Coklat mini & 4 & $3.45 \%$ \\
\hline 68 & Tart & 1 & $13.79 \%$ \\
\hline 69 & Tawar 7 Rasa & 1 & $3.45 \%$ \\
\hline 70 & Tawar Kering Bungkus & 2 & $3.45 \%$ \\
\hline 71 & Tawar Kismis & 3 & $6.90 \%$ \\
\hline 72 & Tawar Moca Ceres & & $10.34 \%$ \\
\hline 73 & Tawar Pandan & $3.45 \%$ \\
\hline 74 & Tawar Petak Originl & $10.34 \%$ \\
\hline
\end{tabular}

Berdasarkan tabel 2 yang berisi item-item dengan nilai support yang dimilikinya, dengan menetapkan minimum support $\geq 25 \%$ maka item yang memenuhi nilai minimum support $\geq 25 \%$ terlihat pada tabel 3 .

Tabel 3. Item dengan Minimum Support $\geq 25 \%$

\begin{tabular}{cccc}
\hline No & Item & Quantity & Support \\
\hline 1 & Roti Aneka Rasa & 20 & $68.97 \%$ \\
\hline 2 & Bika Ambon & 17 & $58.62 \%$ \\
\hline 3 & Donat Aneka Rasa & 14 & $48.28 \%$ \\
\hline 4 & Caramel Pisang & 13 & $44.83 \%$ \\
\hline 5 & Kubas & 12 & $41.38 \%$ \\
\hline 6 & Serba-serbi & 10 & $34.48 \%$ \\
\hline 7 & Paha Ayam & 9 & $31.03 \%$ \\
\hline
\end{tabular}




\subsection{Pembentukan Aturan Asosiasi (Association Rule)}

Untuk menemukan association rule dilakukan tahap-tahap sebelumnya, kemudian akan dihitung nilai confidence dari setiap item dengan rumus[16].

Tabel 4. Itemset dengan Nilai Support dan Confidence

\begin{tabular}{|c|c|c|c|c|c|}
\hline No & Antecedent (A) & Consequent (B) & $\begin{array}{c}\text { Jumlah } \\
\text { Transaksi A } \\
\text { dan B }\end{array}$ & Support & Confidence \\
\hline 1 & Bika Ambon & Caramel Pisang & 6 & $21.43 \%$ & $35.29 \%$ \\
\hline 2 & Caramel Pisang & Paha Ayam & 7 & $25.00 \%$ & $53.85 \%$ \\
\hline 3 & Caramel Pisang & Roti Aneka Rasa & 9 & $32.14 \%$ & $69.23 \%$ \\
\hline 4 & Caramel Pisang & Serba-serbi & 4 & $14.29 \%$ & $30.77 \%$ \\
\hline 5 & $\begin{array}{c}\text { Donat Aneka } \\
\text { Rasa }\end{array}$ & Bika Ambon & 8 & $28.57 \%$ & $57.14 \%$ \\
\hline 6 & $\begin{array}{c}\text { Donat Aneka } \\
\text { Rasa }\end{array}$ & Caramel Pisang & 6 & $21.43 \%$ & $42.86 \%$ \\
\hline 7 & $\begin{array}{c}\text { Donat Aneka } \\
\text { Rasa }\end{array}$ & Kubas & 7 & $25.00 \%$ & $50.00 \%$ \\
\hline 8 & $\begin{array}{c}\text { Donat Aneka } \\
\text { Rasa }\end{array}$ & Paha Ayam & 5 & $17.86 \%$ & $35.71 \%$ \\
\hline 9 & $\begin{array}{c}\text { Donat Aneka } \\
\text { Rasa }\end{array}$ & Roti Aneka Rasa & 11 & $39.29 \%$ & $78.57 \%$ \\
\hline 10 & $\begin{array}{c}\text { Donat Aneka } \\
\text { Rasa }\end{array}$ & Serba-serbi & 2 & $7.14 \%$ & $14.29 \%$ \\
\hline 11 & Kubas & Bika Ambon & 7 & $25.00 \%$ & $58.33 \%$ \\
\hline 12 & Bika Ambon & Donat Aneka Rasa & 8 & $28.57 \%$ & $47.06 \%$ \\
\hline 13 & Kubas & Caramel Pisang & 4 & $14.29 \%$ & $33.33 \%$ \\
\hline 14 & Kubas & Donat Aneka Rasa & 7 & $25.00 \%$ & $58.33 \%$ \\
\hline 15 & Kubas & Paha Ayam & 3 & $10.71 \%$ & $25.00 \%$ \\
\hline 16 & Kubas & Roti Aneka Rasa & 9 & $32.14 \%$ & $75.00 \%$ \\
\hline 17 & Kubas & Serba-serbi & 3 & $10.71 \%$ & $25.00 \%$ \\
\hline 18 & Paha Ayam & Bika Ambon & 5 & $17.86 \%$ & $55.56 \%$ \\
\hline 19 & Paha Ayam & Caramel Pisang & 7 & $25.00 \%$ & $77.78 \%$ \\
\hline 20 & Paha Ayam & Donat Aneka Rasa & 5 & $17.86 \%$ & $55.56 \%$ \\
\hline 21 & Paha Ayam & Kubas & 3 & $10.71 \%$ & $33.33 \%$ \\
\hline 22 & Paha Ayam & Roti Aneka Rasa & 8 & $28.57 \%$ & $88.89 \%$ \\
\hline 23 & Bika Ambon & Kubas & 7 & $25.00 \%$ & $41.18 \%$ \\
\hline 24 & Paha Ayam & Serba-serbi & 3 & $10.71 \%$ & $33.33 \%$ \\
\hline 25 & $\begin{array}{c}\text { Roti Aneka } \\
\text { Rasa }\end{array}$ & Bika Ambon & 12 & $42.86 \%$ & $60.00 \%$ \\
\hline 26 & $\begin{array}{c}\text { Roti Aneka } \\
\text { Rasa }\end{array}$ & Caramel Pisang & 9 & $32.14 \%$ & $45.00 \%$ \\
\hline
\end{tabular}




\begin{tabular}{cccccc}
\hline 27 & $\begin{array}{c}\text { Roti Aneka } \\
\text { Rasa }\end{array}$ & Donat Aneka Rasa & 11 & $39.29 \%$ & $55.00 \%$ \\
\hline 28 & $\begin{array}{c}\text { Roti Aneka } \\
\text { Rasa }\end{array}$ & Kubas & 9 & $32.14 \%$ & $45.00 \%$ \\
\hline 29 & $\begin{array}{c}\text { Roti Aneka } \\
\text { Rasa }\end{array}$ & Paha Ayam & 8 & $28.57 \%$ & $40.00 \%$ \\
\hline 30 & $\begin{array}{c}\text { Roti Aneka } \\
\text { Rasa }\end{array}$ & Serba-serbi & 5 & $17.86 \%$ & $25.00 \%$ \\
\hline 31 & Serba-serbi & Bika Ambon & 5 & $17.86 \%$ & $50.00 \%$ \\
\hline 32 & Serba-serbi & Caramel Pisang & 4 & $14.29 \%$ & $40.00 \%$ \\
\hline 33 & Serba-serbi & Donat Aneka Rasa & 2 & $7.14 \%$ & $20.00 \%$ \\
\hline 34 & Bika Ambon & Paha Ayam & 5 & $17.86 \%$ & $29.41 \%$ \\
\hline 35 & Serba-serbi & Kubas & 3 & $10.71 \%$ & $30.00 \%$ \\
\hline 36 & Serba-serbi & Paha Ayam & 3 & $10.71 \%$ & $30.00 \%$ \\
\hline 37 & Serba-serbi & Roti Aneka Rasa & 5 & $17.86 \%$ & $50.00 \%$ \\
\hline 38 & Bika Ambon & Roti Aneka Rasa & 12 & $42.86 \%$ & $70.59 \%$ \\
\hline 39 & Bika Ambon & Serba-serbi & 5 & $17.86 \%$ & $29.41 \%$ \\
\hline 40 & Caramel Pisang & Bika Ambon & 6 & $21.43 \%$ & $46.15 \%$ \\
\hline 41 & Caramel Pisang & Donat Aneka Rasa & 6 & $21.43 \%$ & $46.15 \%$ \\
\hline 42 & Caramel Pisang & Kubas & 4 & $14.29 \%$ & $30.77 \%$ \\
\hline & & & & \\
\hline & & & & \\
\hline
\end{tabular}

Hasil perhitungan pada tabel 4 dengan nilai confidence diperoleh dengan sample perhitungan sebagaiberikut [17]:

Setelah diperoleh nilai Confidence, maka diambil data itemset yang memenuhi minimum Confidence $=60 \%$ sebagai berikut.

Tabel 5. Itemset dengan Nilai Minimum Support dan Minimum Confidence

\begin{tabular}{cccccc}
\hline No & Antecedent (A) & Consequent (B) & $\begin{array}{c}\text { Jumlah } \\
\text { Transaks } \\
\text { iA dan } \\
\text { B }\end{array}$ & Support & Confidence \\
& & \multicolumn{5}{c}{} & \\
\hline 1 & Paha Ayam & Roti Aneka Rasa & 8 & $28.57 \%$ & $88.89 \%$ \\
\hline 2 & Donat Aneka Rasa & Roti Aneka Rasa & 11 & $39.29 \%$ & $78.57 \%$ \\
\hline 3 & Paha Ayam & Caramel Pisang & 7 & $25.00 \%$ & $77.78 \%$ \\
\hline 4 & Kubas & Roti Aneka Rasa & 9 & $32.14 \%$ & $75.00 \%$ \\
\hline 5 & Bika Ambon & Roti Aneka Rasa & 12 & $42.86 \%$ & $70.59 \%$ \\
\hline 6 & Caramel Pisang & Roti Aneka Rasa & 9 & $32.14 \%$ & $69.23 \%$ \\
\hline 7 & Roti Aneka Rasa & Bika Ambon & 12 & $42.86 \%$ & $60.00 \%$ \\
\hline
\end{tabular}


Dari tahap-tahap yang telah dilakukan diatas, maka item yang memenuhi minimum confidence $=60 \%$ pada tabel 5 dan dapat diambil kesimpulan sebagai berikut:

1. Jika pelanggan membeli Paha Ayam maka pelanggan juga akan membeli Roti Aneka Rasa dengan nilai support $=28,57 \%$ dan confidence $=88.89 \%$.

2. Jika pelanggan membeli Donat Aneka Rasa maka pelanggan juga akan membeli Roti Aneka Rasadengan nilai support $=39,29 \%$ confidence $=78,57 \%$

3. Jika pelanggan membeli Paha Ayam maka pelanggan juga akan membeli Caramel Pisang dengan nilai support $=25 \%$ confidence $=77,78 \%$

4. Jika pelanggan membeli Kubas maka pelanggan juga akan membeli Roti Aneka Rasa dengan nilai support $=32,14 \%$ confidence $=75 \%$

5. Jika pelanggan membeli Bika Ambon maka pelanggan juga akan membeli Roti Aneka Rasa dengan nilai support $=42,86 \%$ confidence $=70,59 \%$

6. Jika pelanggan membeli Caramel Pisang maka pelanggan juga akan membeli Roti Aneka Rasa dengannilai support $=32,14 \%$ confidence $=69,23 \%$

7. Jika pelanggan membeli Roti Aneka Rasa maka pelanggan juga akan membeli Bika Ambon dengan nilai support $=42,86 \%$ confidence $=60 \%$

\section{KESIMPULAN}

Berdasarkan dari bahasan di atas dapat diambil kesimpulan sebagai berikut :

1. Penerapan Data Mining dengan menggunakan algoritma apriori dapat menentukan pola penjualanmakana ringan sehingga produsen bisa menjaga stok makanan ringan lebih efesien.

2. Dengan pola asosiasi yang dihasilkan dari algoritma apriori, produsen bisa lebih mengedepankan polapenjualan untuk menentukan stok makanan ringan tersebut.

3. Hasil penelitian ini mempengaruhi jumlah stok makanan ringan yang banyak dan sedikit.

\section{REFERENSI}

[1] A. Azwar, “Algorithm Apriori Use for a Consumer Behavior in," Sains dan Inform., vol. 1, pp. 45-59, 2015.

[2] H. Kusumo, E. Sediyono, and M. Marwata, "Analisis Algoritma Apriori untuk Mendukung Strategi Promosi Perguruan Tinggi,” Walisongo J. Inf. Technol., vol. 1, no. 1, p. 49, 2019, doi: 10.21580/wjit.2019.1.1.4000.

[3] R. Ruswati, A. I. Gufroni, and R. Rianto, "Associative Analysis Data Mining Pattern Against Traffic Accidents Using Apriori Algorithm,” Sci. J. Informatics, vol. 5, no. 2, pp. 91-104, 2018, doi: 10.15294/sji.v5i2.16199.

[4] A. A. Agustian and A. Bisri, "Data Mining Optimization Using Sample Bootstrapping and Particle Swarm Optimization in the Credit Approval Classification," Indones. J. Artif. Intell. Data Min., vol. 2, no. 1, pp. 18 27, 2019, doi: 10.24014/ijaidm.v2i1.6299.

[5] L. I. Prahartiwi and W. Dari, "Algoritma Apriori untuk Pencarian Frequent itemset dalam Association Rule Mining," PIKSEL Penelit. Ilmu Komput. Sist. Embed. Log., vol. 7, no. 2, pp. 143-152, 2019, doi: 10.33558/piksel.v7i2.1817.

[6] R. Yanto and R. Khoiriah, "Implementasi Data Mining dengan Metode Algoritma Apriori dalam Menentukan Pola Pembelian Obat," Creat. Inf. Technol. J., vol. 2, no. 2, p. 102, 2015, doi: 10.24076/citec.2015v2i2.41.

[7] S. Rodiyansyah, "Algoritma Apriori untuk Analisis Keranjang Belanja pada Data Transaksi Penjualan," Infotech J., vol. 1, no. 2, p. 236599, 2015.

[8] N. Walia and A. Kalia, “Association rule mining for stock data," Int. J. Adv. Sci. Technol., vol. 28, no. 19, pp. 796- 802, 2019.

[9] I. Suana, "Vol . 2 No . 1 Juni Tahun 2020 ISSN 2722-3612 Vol . 2 No . 1 Juni Tahun 2020,” vol. 2, no. 1, pp. 25-35,2020. 
[10] A. R. Riszky and M. Sadikin, "Data Mining Menggunakan Algoritma Apriori untuk Rekomendasi Produk bagi Pelanggan,” J. Teknol. dan Sist. Komput., vol. 7, no. 3, p. 103, 2019, doi: 10.14710/jtsiskom.7.3.2019.103108.

[11] W. Choiriah, "Penggunaan Algorithma Apriori Data Mining Untuk Mengetahui Tingkatkesetiaan Konsumen (Brand Loyality) Terhadap Merek Kenderaan Bermotor (Studi Kasus Dealer Honda Rumbai)," J. Teknol. Inf. Komun. Digit. Zo., vol. 7, no. 1, p. 44, 2016.

[12] K. Shaukat, S. Zaheer, and I. Nawaz, “Association Rule Mining: An Application Perspective," Int. J. Comput. Sci. Innov., vol. 2015, no. 1, pp. 29-38, 2017.

[13] A. H. Nasyuha, Zulham, I. Jang Cik, M. Amin, S. Candra Setia, and D. Siregar, "An Integrated Multi Criteria Decision Making Method for Fashion Selection," J. Phys. Conf. Ser., vol. 1424, no. 1, 2019, doi: 10.1088/1742- 6596/1424/1/012030.

[14] A. Ariya, "Stock Forecasting by Association Rule Mining," Proc. 21st Asia-Pacific Conf. Glob. Business, Econ. Financ. Soc. Sci. (AP18Taiwan Conf., pp. 1-8, 2018.

[15] K. A. Baffour and A. F. Adekoya, "A Modified Apriori Algorithm For Fast And Accurate Generation Of Frequent Item Sets,” Int. J. Sci. Technol. Res., vol. 06, no. 08, pp. 169-173, 2017.

[16] R. N. Saputra, M. T. Furqon, and Indriati, "Implementasi Association Rule Mining Untuk Menentukan Menu Paket Makanan Dengan Algoritma FIN Menggunakan Nodesets," J. Pengemb. Teknol. Inf. dan Ilmu Komput. Univ. Brawijaya, vol. 2, no. 10, pp. 3962-3967, 2018.

[17] W. Aprianti, J. Permadi, and Oktaviyani, "Penerapan Algoritma Apriori untuk Transaksi Penjualan Obat padaApotek Azka,"Semin. Nas. Mat. dan Apl., no. February, pp. 436-442, 2017. 